\title{
Luminescence Characteristics of Feldspar from Nigeria
}

\author{
Janet A. Ademola \\ Department of Physics, University of Ibadan, Ibadan, Nigeria \\ Email: jaaademola@yahoo.com, janet.ademola@mail.ui.edu.ng
}

Received 1 June 2014; revised 30 June 2014; accepted 8 July 2014

Copyright (C) 2014 by author and Scientific Research Publishing Inc. This work is licensed under the Creative Commons Attribution International License (CC BY). http://creativecommons.org/licenses/by/4.0/

\section{(c) (7) Open Access}

\begin{abstract}
The luminescence characteristics of feldspar from Nigeria were investigated. Without preheat treatment, the TL glow curve exhibited two peaks at $136^{\circ} \mathrm{C}$ and $175^{\circ} \mathrm{C}$. When preheated to a temperature of $200^{\circ} \mathrm{C}$ only one peak was observed at $240^{\circ} \mathrm{C}$. The highest net IRSL intensity was obtained for a stimulation temperature of $250^{\circ} \mathrm{C}$. The TL signal is reduced by IR stimulation, and the longer the stimulation the more pronounced the effect. The dose response curves for both the TL and the IRSL showed a linear relationship for the doses considered in the study. Dose recovery test performed using the SAR method showed consistency with given dose for both TL and IRSL.
\end{abstract}

\section{Keywords}

Feldspar, TL, IRSL, Nigeria

\section{Introduction}

Many natural minerals exhibit luminescence properties that are suitable for dating and dosimetry applications. Among the minerals with luminescence properties, quartz and feldspar are the most used ones. Feldspars are attractive dosimeters for luminescence dating because of their higher saturation dose and widespread availability compared to quartz [1]. Feldspar generally gives brighter luminescence signal than quartz and as its level of saturation dose is much higher it can provide a better estimate of burial age for older sediment [2].

Duller (1997) summarized the advantages of feldspar in luminescence applications as follows [3]: 1) in geological samples feldspars typically have a higher intrinsic luminescence brightness than quartz, which means that they can be used to measure smaller absorbed radiation doses; 2) certain types of feldspar contain a significant proportion of potassium, whose radioactive isotope $\left({ }^{40} \mathrm{~K}\right)$ can contribute a large percentage of the total ionizing radiation dose to the sample. This "internal" component is unaffected by variations in interstitial water or in the thickness of the overburden, and hence the overall uncertainty in the dose rate is reduced; 3) the possibili- 
ty to obtain an infrared stimulated luminescence (IRSL) signal from feldspars using stimulation from 800 to $950 \mathrm{~nm}$ discovered by Hütt et al. (1988) [4]. Over the past few years feldspar IRSL dating has received increasing attention [5]-[8]. The luminescence properties of minerals are affected by a number of factors which include the origin, the composition, the radioactivity, the age, the temperature and the pressure [9]. Luminescence characteristics of feldspar of different origins have been investigated [10]-[15]. Previous work has identified high temperature TL peaks $\left(310^{\circ} \mathrm{C}, 330^{\circ} \mathrm{C}, 400^{\circ} \mathrm{C}\right.$, between $410^{\circ} \mathrm{C}$ and $420^{\circ} \mathrm{C}$ ) [3] [16] [17]. Murray et al. (2009) reported that high temperature source is responsible for the majority of IRSL signal [17]. Gliganic et al. (2012) reported difference in the dependence of the shape of the net IRSL decay curve on stimulation temperature for samples from different locations. They concluded that the observed difference in the rate and pattern of the net IRSL decay as a function of stimulation temperature suggested that the process of IRSL production may vary between samples [12].

This study aims at investigating the luminescence properties of feldspar collected from a mining site in Ibadan, Southwestern Nigeria. These include the relationship between TL and IRSL signals, the effect of stimulation temperature on IRSL, the dose response of IRSL and TL signals and dose recovery test using the SAR method.

\section{Materials and Method}

Feldspar mineral was sourced from a mining site in Ibadan, Southwestern Nigeria. According to Itiola (1998), the area host pegmatite [18]. Pegmatite is known to host a wide range of minerals, both metallic and non-metallic. The area is thus rich in minerals like mica, feldspar, lepidolite, quartz etc. The feldspar sample was pulverized and treated with $10 \% \mathrm{HCl}$ to remove carbonate matter. It was then washed with distill water, wet sieved and kept in the oven at a temperature of $50^{\circ} \mathrm{C}$ to dry. Samples were fixed on plantchet covered with light silicon spray. The TL and IRSL measurements were performed on a Risø TL/OSL-DA-15 reader equipped with $\mathrm{a}^{90} \mathrm{Sr} /{ }^{90} \mathrm{Y}$ beta source and a $7.5 \mathrm{~mm} \mathrm{U}-340$ Hoya filter.

\section{Results and Discussion}

\subsection{TL Glow and IRSL Decay Curves}

The TL glow curve and IRSL decay curve for a beta dose of 820 mGy are shown in Figure 1(a) and Figure 1 (b), respectively. For the TL, the sample was heated to a temperature of $500^{\circ} \mathrm{C}$ before irradiation. TL measurement was performed for a $\mathrm{T}_{\max }$ of $500^{\circ} \mathrm{C}$ at a heating rate of $5^{\circ} \mathrm{C} / \mathrm{s}$. Two peaks were observed at temperatures of $\sim 136^{\circ} \mathrm{C}$ and $\sim 175^{\circ} \mathrm{C}$. No high temperature peak was observed as reported in previous work [3] [12] [16] [17]. This could be due to the origin of the feldspar used in this study. The IRSL signal was measured at room temperature for $100 \mathrm{~s}$. The sample showed IRSL sensitivity.
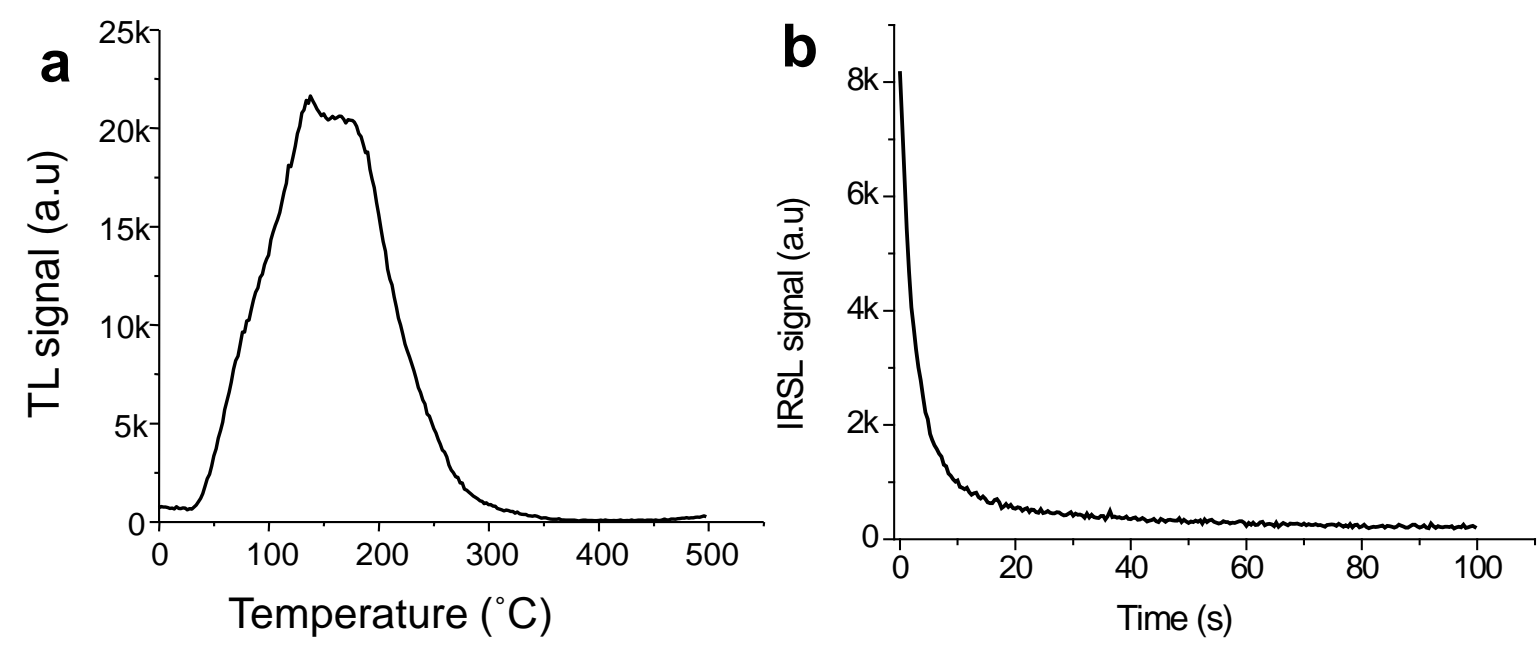

Figure 1. (a) Thermoluminescence glow curve of feldspar at $\mathrm{T}_{\max }$ of $500^{\circ} \mathrm{C}$ at a heating rate of $5^{\circ} \mathrm{C} / \mathrm{s}$ for a beta dose of $820 \mathrm{mGy}$; (b) IRSL decay curve of feldspar taken at room temperature for a beta dose of $820 \mathrm{mGy}$. 


\subsection{Characterising the Relationship between TL and IRSL}

The relationship between TL and IRSL signals was investigated employing the approach used by Gliganic et al. (2012) [12]. Two aliquots were heated to a temperature of $500^{\circ} \mathrm{C}$ and then irradiated with a beta dose of 2 Gy. This was immediately followed by TL measurement at $\mathrm{T}_{\max }$ of $500^{\circ} \mathrm{C}$ with a heating rate of $5^{\circ} \mathrm{C} / \mathrm{s}$. After the first measurement the samples were irradiated with same dose and preheated to a temperature of $200^{\circ} \mathrm{C}$ at a heating rate of $5^{\circ} \mathrm{C} / \mathrm{s}$ and maintained for $10 \mathrm{~s}$ before the second TL measurement. Third TL measurement was done after irradiation, preheat and IR stimulation at $50^{\circ} \mathrm{C}$ for $100 \mathrm{~s}$. The TL glow curves for the three different treatments are shown in Figure 2(a). The TL measurement taken immediately after irradiation showed two peaks at $\sim 138^{\circ} \mathrm{C}$ and $\sim 179^{\circ} \mathrm{C}$ (as in Figure 1(a)). Only one peak was observed at a temperature of about $240^{\circ} \mathrm{C}$ following preheat after irradiation. The TL signals with preheat treatments were integrated between $200^{\circ} \mathrm{C}$ and $300^{\circ} \mathrm{C}$ and the intensities subtracted. There was a reduction of about $89 \%$ in intensity for each of the aliquot. This shows that IR is able to remove charge from traps which are responsible for the TL peak. The signal of the preheat plus IR was subtracted from that of the preheat signal to obtained the loss TL (Figure 2(b)). Much of the signal was lost between $158^{\circ} \mathrm{C}$ and $334^{\circ} \mathrm{C}$. This result suggests that the IRSL may be associated with this temperature region.

\subsection{Effect of IR Stimulation Temperature on IRSL Decay Curve}

The intensity of the total integrated IRSL signal of feldspars is observed to increase with increasing stimulation temperature [19] [20]. It is also reported that the decay rate of the IRSL signal increased with stimulation temperature [19] [20]. According to the latter authors [20], this increase is due to a thermally assisted process of recombination. In contrast, Poolton et al. (2002) found that the form of the decay is not affected by stimulation temperature [21]. Thomsen et al. (2008) also reported that the rate of IRSL decay is not dependent on stimulation temperature, prompting them to suggest that tunneling recombination dominates IRSL production and thermal assistance is not significant [22].

The effect of temperature of IR stimulation on the IRSL signal was examined. Feldspar sample was heated to a temperature of $500^{\circ} \mathrm{C}$ to remove the natural signal, given a dose of $2 \mathrm{~Gy}$ and preheated to a temperature of $200^{\circ} \mathrm{C}$. IRSL was acquired using different stimulation temperatures ranging between $50^{\circ} \mathrm{C}$ and $500^{\circ} \mathrm{C}$ in the increment of $50^{\circ} \mathrm{C}$. The IRSL decay curves are presented in Figure 3(a) and Figure 3(b). Figure 3(c) shows the relationship between the net IRSL intensity and stimulation temperature. The net IRSL intensity (summation of the first $2 \mathrm{~s}$ signal minus the background, the summation of the last $10 \mathrm{~s}$ ) increases as the stimulation temperature is increased to $250^{\circ} \mathrm{C}$, above which it decreases with temperature. This is in agreement with the observation of Duller and Wintle (1991) and McKeever et al. (1997) [19] [20]. This informed the choice of $250^{\circ} \mathrm{C}$ IR stimulation temperature for the dose recovery test in Section 3.6.
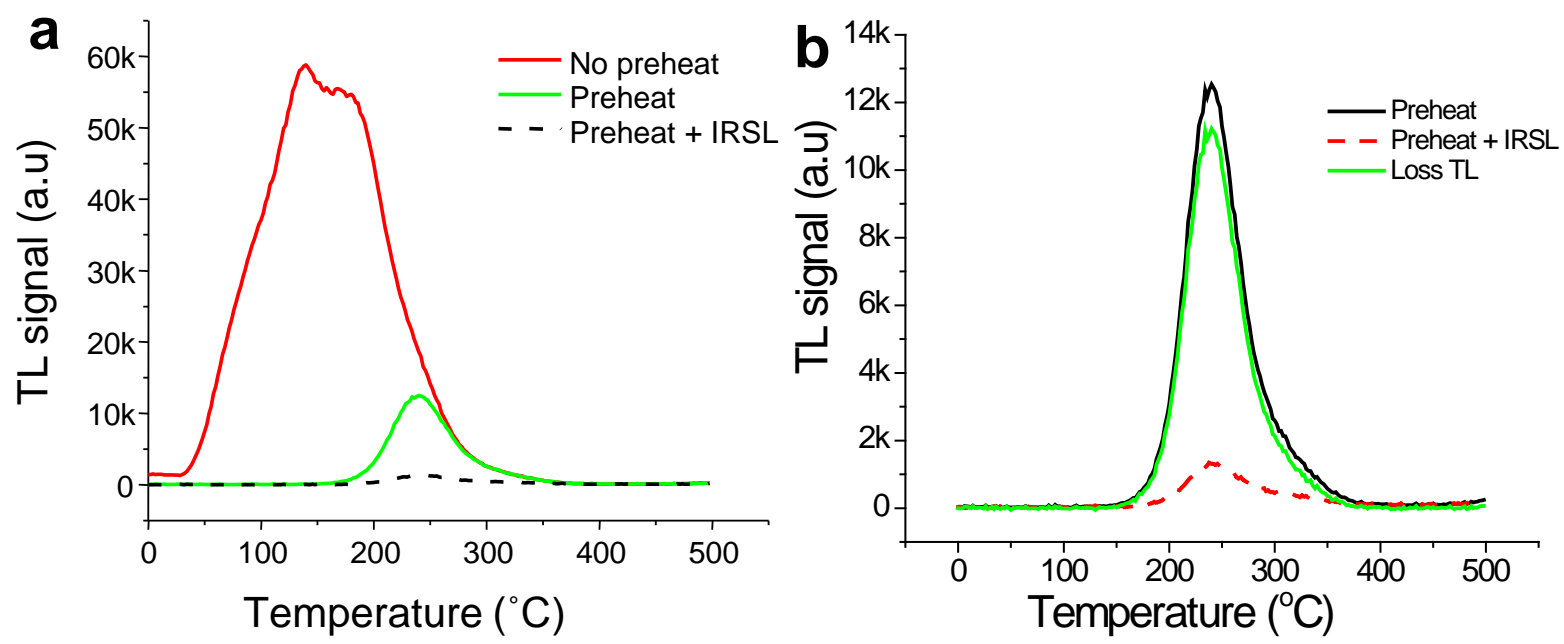

Figure 2. (a) TL glow curves for different treatment before measurement; (b) TL glow curves for different treatment and the lost signal. 

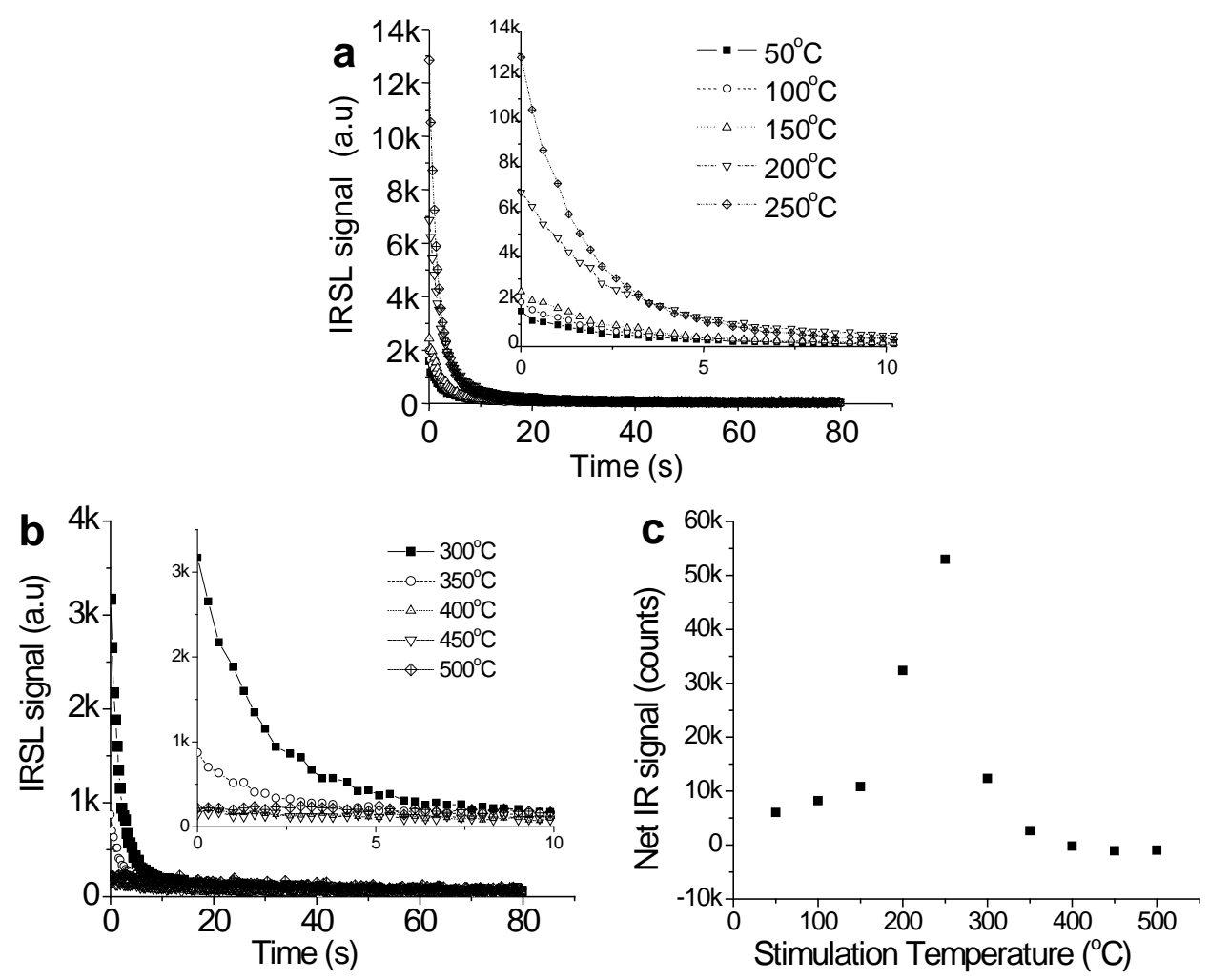

Figure 3. (a) (b) IRSL decay curves at different stimulation temperatures; (c) The plot of net IRSL intensity against stimulation temperature.

\subsection{Effect of Prior IR Stimulation on TL}

The effect of prior IR stimulation on TL trap stability was investigated. Two aliquots were heated to a temperature of $500^{\circ} \mathrm{C}$ to remove the natural signal and then irradiated with a beta dose of $2 \mathrm{~Gy}$. The irradiated samples were preheated to a temperature of $200^{\circ} \mathrm{C}$ at a heating rate of $5^{\circ} \mathrm{C} / \mathrm{s}$ and maintained for $10 \mathrm{~s}$. Samples were then illuminated with IR for different times. TL measurement was done at a temperature of $500^{\circ} \mathrm{C}$ with a heating rate of $5^{\circ} \mathrm{C} / \mathrm{s}$ after each illumination. The effect of $0,1,10,100$ and $1000 \mathrm{~s}$ of IR stimulation on the TL signal is shown in Figure 4(a). As shown in the figure, TL signal is reduced by IR stimulation and the longer the stimulation, the more pronounced the effect. Unlike those reported by Panzeri et al. (2012), there was no emission at low temperature due to phototransfer (see insect) [14]. The TL signals after IR stimulation subtracted from the TL signal without stimulation is shown in Figure 4(b). The lost TL signal shows that the $240^{\circ} \mathrm{C}$ peak is reduced by IR stimulation. It is also observed that there is no shift in the peak position of the lost TL signal.

\subsection{Dose Response}

The dependence of TL and IRSL intensities on dose was examined. TL and IRSL signals were measured for doses ranging from 0.41 to $3.29 \mathrm{~Gy}$. The TL intensity was obtained by integrating from $200^{\circ} \mathrm{C}$ to $300^{\circ} \mathrm{C}$ and that of the IRSL was obtained from the first $2 \mathrm{~s}$. The dose response curves for the IRSL and TL are shown in Figure 5(a) and Figure 5(b), respectively. Both the IRSL and TL exhibited a linear response in the range of the doses considered.

\subsection{Dose Recovery Test}

Dose recovery experiments were performed using five aliquots each for TL and IRSL. A laboratory dose of 2.47 Gy was given to each aliquot. Samples were heated to a temperature of $500^{\circ} \mathrm{C}$ in order to remove the natural signal. They were irradiated with beta dose, preheated to a temperature of $200^{\circ} \mathrm{C}$ at a heating rate of $5^{\circ} \mathrm{C} / \mathrm{s}$ and maintained for $10 \mathrm{~s}$. TL measurements was done for $\mathrm{T}_{\max }$ of $400^{\circ} \mathrm{C}$ at a heating rate of $5^{\circ} \mathrm{C} / \mathrm{s}$. IRSL was done at a 
stimulation temperature of $250^{\circ} \mathrm{C}$ for $80 \mathrm{~s}$. The well established SAR protocol was employed using six regeneration doses with the first regeneration dose recycled. A test dose of 0.41 Gy was administered. All the aliquots for both IRSL and TL passed the criteria of a good recycling ratio and a very low recuperation effect. This suggests good repeatability of sensitivity-corrected luminescence signal [13] [23].

The ratio of the measured dose to the given dose is shown in Figure 6(a) and Figure 6(b) for IRSL and TL, respectively. The known doses for the IRSL and TL could be recovered to within $6 \%$. The dose recovered for the IRSL measurement ranged between 2.33 and $2.53 \mathrm{~Gy}$ with a mean value of $2.42 \pm 0.09 \mathrm{~Gy}$. That of the TL ranged between 2.56 and 2.59 Gy with a mean value of $2.57 \pm 0.02$ Gy. The errors quoted are standard deviations of the mean values. No significant overestimation was observed in the recovered doses. This suggests that the currently applied SAR is applicable to the sample considered in this work.
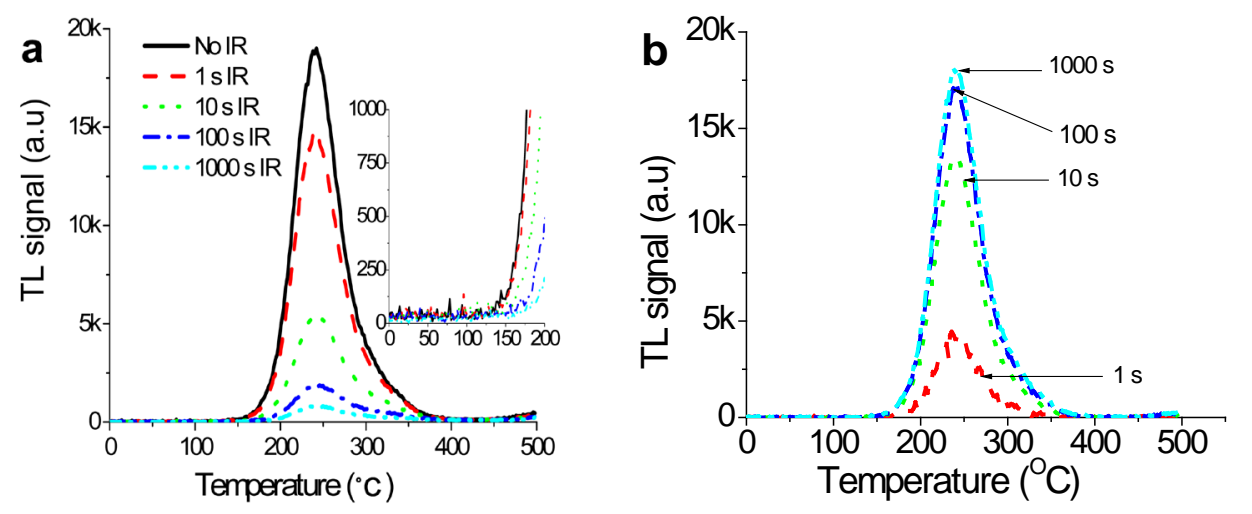

Figure 4. (a) The effect of IR stimulation time on TL; (b) the lost signals for the different IR stimulation time.
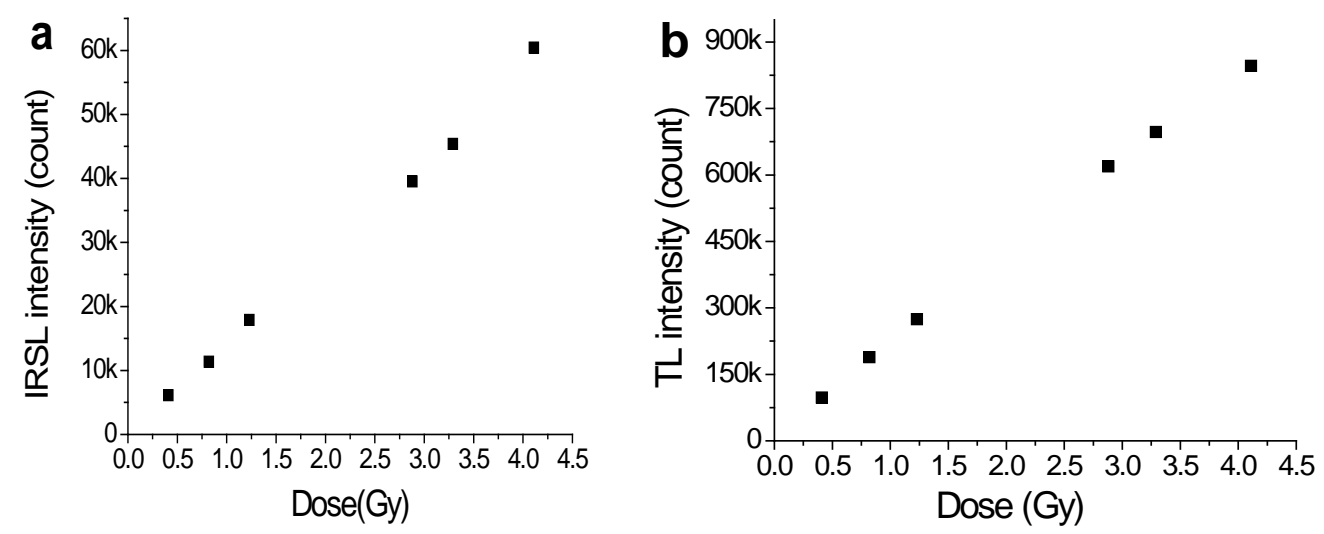

Figure 5. The relationships between the intensity and dose for (a) IRSL signal and (b) TL signal.
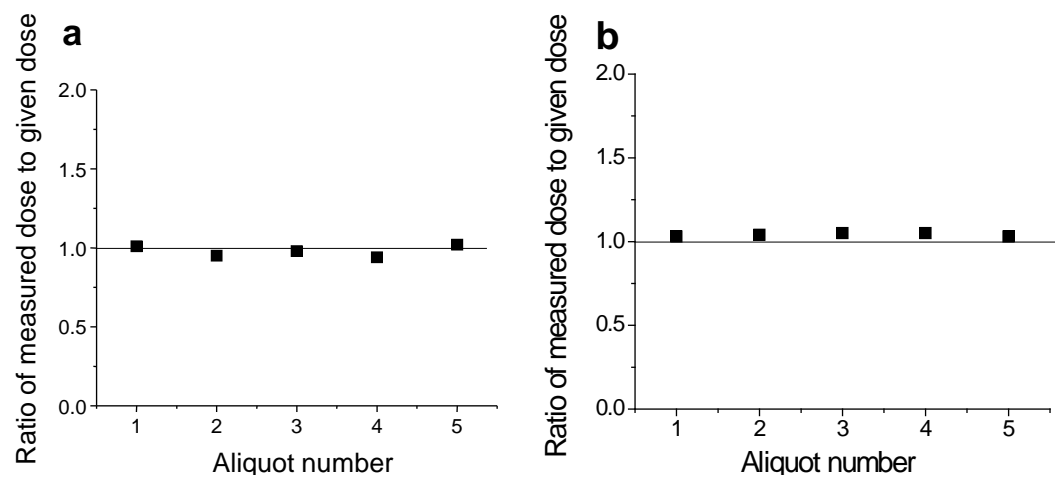

Figure 6. The ratio of measured dose to given dose for dose recovery test for a given dose of $2.47 \mathrm{~Gy}$. (a) Infrared stimulated luminescence; (b) Thermoluminescence. 


\section{Conclusion}

Luminescence characteristics of feldspar obtained from Ibadan, Southwestern Nigerian have been investigated in order to examine its potential for dosimetry. The feldspar sample exhibited a strong radiation-induced TL and IRSL signals. Unlike previous studies no high temperature TL peak was observed. No emission at low temperature due to phototransfer was observed in prior IR stimulation on TL. The IRSL stimulation temperature of $250^{\circ} \mathrm{C}$ resulted in the maximum obtained net IRSL intensity. The dose response curves for both the TL and IRSL exhibited a linear relationship. The results of dose recovery tests showed no significant overestimation of the recovered doses. Further investigation on the effect of stimulation temperature on anomalous fading of the feldspar will be carried out.

\section{Acknowledgements}

The author would like thank the Alexander von Humboldt Foundation for the fellowship award and Dr. C Woda and all the other members of Anthropogenic Environmental Radiation research group of the Institute of Radiation Protection, Helmholtz Zentrum München.

\section{References}

[1] Larsen, A., Greilich, S., Jain, M. and Murray, A.S. (2009) Developing a Numerical Simulation for Fading in Feldspar. Radiation Measurements, 44, 461-471. http://dx.doi.org/10.1016/j.radmeas.2009.03.035

[2] Alappat, L., Tsukamoto, S., Singh, P., Srikanth, D., Ramesh, R. and Frechen, M. (2010) Chronology of Cauvery Delta Sediments from Shallow Subsurface Cores Using Elevated-Temperature Post-IR-IRSL Dating of Feldspar. Geochronometria, 37, 37-47. http://dx.doi.org/10.2478/v10003-010-0025-1

[3] Duller, G.A.T. (1997) Behavioural Studies of Stimulated Luminescence from Feldspars. Radiation Measurements, 27, 663-694. http://dx.doi.org/10.1016/S1350-4487(97)00216-3

[4] Hütt, G., Jaek, I. and Tchonka, J. (1988) Optical Dating: K-Feldspar Optical Response Stimulation Spectra. Quaternary Science Review, 7, 381-385. http://dx.doi.org/10.1016/0277-3791(88)90033-9

[5] Barnett, S.M. and Bailiff, I.K. (1997) Infrared Stimulation Spectra of Sediment Containing Feldspar. Radiation Measurements, 27, 237-242. http://dx.doi.org/10.1016/S1350-4487(96)00116-3

[6] Auclair, M., Lamothe, M., Lagroix, F. and Banerjee, S.K. (2007) Luminescence Investigations of Loess and Tephra from Halfway House Section, Central Alaska. Quaternary Geochronology, 2, 34-38. http://dx.doi.org/10.1016/j.quageo.2006.05.009

[7] Wallinga, J., Boss, A.J.J., Dorenbos, P., Murray, A.S. and Schokker, J. (2007) A Test Case for Anomalous Fading Correction in IRSL Dating. Quaternary Geochronology, 2, 216-221. http://dx.doi.org/10.1016/j.quageo.2006.05.014

[8] Buylaert, J.P., Murray, A.S., Thomsen, K.J. and Jain, M. (2009) Testing the Potential of an Elevated Temperature IRSL Signal from K-Feldspar. Radiation Measurements, 44, 560-565. http://dx.doi.org/10.1016/j.radmeas.2009.02.007

[9] Blanchard, F.N. (1966) Thermoluminescence of Fluorite and Age Deposition. American Mineralogist, 51.

[10] Kars, R.H., Wallinga, J. and Cohen, K.M. (2008) A New Approach towards Anomalous Fading Correction for Feldspar IRSL Dating-Test on Sample Field Saturation. Radiation Measurements, 43, 786-790. http://dx.doi.org/10.1016/j.radmeas.2008.01.021

[11] Jaiswal, M.K., Bhat, M.I., Bali, B.S., Ahmad, S. and Chen, Y.G. (2009) Luminescence Characteristics of Quartz and Feldspar from Tectonically Uplifted Terraces in Kashmir Basin, Jammu and Kashmir, India. Radiation Measurements, 44, 523-528. Http://Dx.Doi.Org/10.1016/J.Radmeas.2009.04.008

[12] Gliganic, L.A., Roberts, R.G. and Jacobs, Z. (2012) Natural Variation in the Properties of TL and IRSL Emission from Metamorphic and Volcanic K-Feldspar from East Africa: Assessing Their Reliability for Dating. Radiation Measurements, 47, 659-664. http://dx.doi.org/10.1016/j.radmeas.2012.03.001

[13] Lawson, M.J., Roder, B.J., Stang, D.M. and Rhodes, E.J. (2012) OSL and IRSL Characteristics of Quartz and Feldspar from Southern California, USA. Radiation Measurements, 47, 830-836. http://dx.doi.org/10.1016/j.radmeas.2012.03.025

[14] Panzeri, L., Martini, M. and Sibilia, E. (2012) Effects of Thermal Treatments on Luminescence Features of Three Natural Feldspar. Radiation Measurements, 47, 877-882. http://dx.doi.org/10.1016/j.radmeas.2012.04.018

[15] Lamothe, M., Barré, M., Huot, S. and Ouimet, S. (2012) Natural Luminescence and Anomalous Fading in K-Feldspar. Radiation Measurements, 47, 682-687. http://dx.doi.org/10.1016/j.radmeas.2012.04.018

[16] Duller, G.A.T. and Bøtter-Jensen, L. (1993) Luminescence from Potassium Feldspars Stimulated by Infrared and 
Green Light. Radiation Protection Dosimetry, 47, 683-688.

[17] Murray, A.S., Buylaert, J.P., Thomsen, K.J. and Jain, M. (2009) The Effect of Preheating on the IRSL Signal from Feldspar. Radiation Measurements, 44, 554-559. http://dx.doi.org/10.1016/j.radmeas.2009.02.004

[18] Itiola, O.A. (1998) Aspect of Economic Geology of Olode-Falansa Pegmatite Deposit, Ibadan, South-Western Nigeria. M.Sc. Project, Department of Geology, University of Ibadan, Ibadan.

[19] Duller, G.A.T. and Wintle, A.G. (1991) On Infrared Stimulated Luminescence at Elevated Temperatures. International Journal of Radiation Applications and Instrumentation, Part D, Nuclear Tracks and Radiation Measurement, 18, 379384. http://dx.doi.org/10.1016/1359-0189(91)90003-Z

[20] McKeever, S.W.S., Bøtter-Jensen, L., Larsen, N.A. and Duller, G.A.T. (1997) Temperature Dependence on OSL Decay Curves: Experimental and Theoretical Aspects. Radiation Measurements, 27, 161-170. http://dx.doi.org/10.1016/S1350-4487(96)00106-0

[21] Poolton, N.R.J., Ozanyan, K.B., Wallinga, J., Murray, A.S. and Bøtter-Jensen, L. (2002) Electrons in Feldspar II: A Consideration of the Influence of Conduction Band-Tail States on Luminescence Processes. Physics and Chemistry of Minerals, 29, 217-225. http://dx.doi.org/10.1007/s00269-001-0218-2

[22] Thomsen, K.J., Murray, A.S., Jain, M. and Bøtter-Jensen, L. (2008) Laboratory Fading Rates of Various Luminescence Signals from Feldspar-Rich Sediment Extracts. Radiation Measurements, 43, 1474-1486. http://dx.doi.org/10.1016/j.radmeas.2008.06.002

[23] Duller, G.A.T. (2008) Luminescence Dating: Guidelines on Using Luminescence Dating in Archaeology. English Heritage, Swindon. 
Scientific Research Publishing (SCIRP) is one of the largest Open Access journal publishers. It is currently publishing more than 200 open access, online, peer-reviewed journals covering a wide range of academic disciplines. SCIRP serves the worldwide academic communities and contributes to the progress and application of science with its publication.

Other selected journals from SCIRP are listed as below. Submit your manuscript to us via either submit@scirp.org or Online Submission Portal.
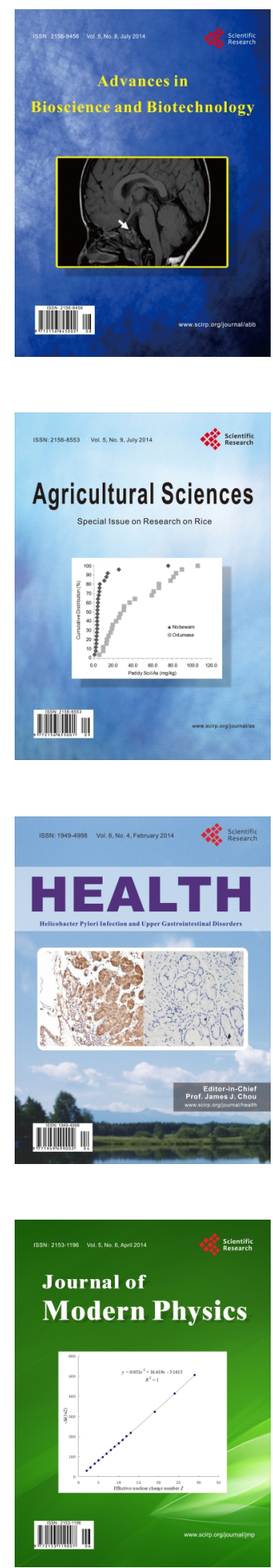
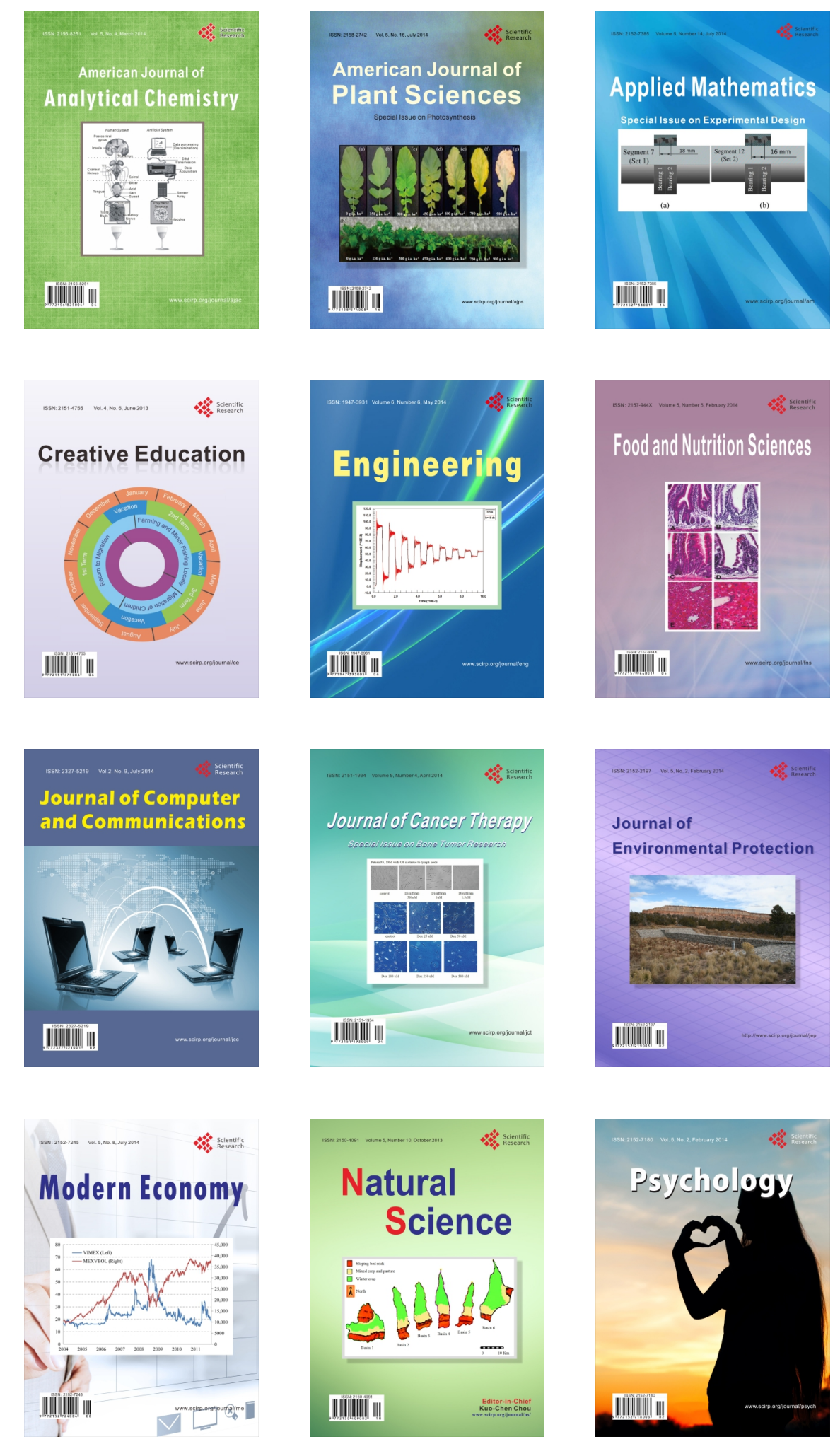